\title{
DIAGNÓSTICO AMBIENTAL INICIAL NO SETOR PRODUTIVO DE UMA EMPRESA DE ALUMINIO SECUNDARIO PELA ISO 14001 E PELO CONCEITO DA PRODUÇÃO MAIS LIMPA
}

\section{INITIAL ENVIRONMENT DIAGNOSIS IN THE PRODUCTIVE SECTOR OF A SECONDARY ALUMINUM COMPANY BY ISO 14001 AND BY THE CONCEPT OF CLEANER PRODUCTION}

\author{
Caroline Rodrigues Vaz ${ }^{1}$; Alexandre Borges Fagundes ${ }^{2}$; Ivanir Luiz de Oliveira ${ }^{3}$ \\ ${ }^{1}$ Universidade Tecnológica Federal do Paraná - UTFPR - Ponta Grossa - Brasil \\ caroline-vaz@hotmail.com \\ ${ }^{2}$ Universidade Tecnológica Federal do Paraná - UTFPR - Ponta Grossa - Brasil \\ borges.fagundes@gmail.com \\ ${ }^{3}$ Universidade Tecnológica Federal do Paraná - UTFPR - Ponta Grossa - Brasil \\ ivanir@utfpr.edu.br
}

\begin{abstract}
Resumo
A aplicação de conceitos ambientais vem se apresentando de forma cada vez mais contundente como fator base para o fomento à sustentabilidade das organizações. Nesse interim os Sistemas de Gestão Ambiental apresentam-se como ferramentas imprescindiveis para o alinhamento e melhor utilização desses conceitos. Em vista disso, este artigo buscou exemplificar a aplicação da norma ISO 14001, no tocante ao Diagnóstico Ambiental Inicial, no setor produtivo de uma empresa de alumínio secundário na cidade de Ponta Grossa-PR, evidenciando os aspectos e impactos ambientais, bem como as potenciais melhorias detectadas nas atividades envolvendo desde o recebimento de matérias-primas até a obtenção dos lingotes com a composição química exigida pelo cliente. O tema a princípio é contextualizado frente à evolução das tendências ambientalistas e é feita uma revisão bibliográfica sobre ISO 14001 e o conceito de Produção mais Limpa, seguidos das respectivas análises sobre o estudo de caso efetuado tornando evidente que a aplicação desse Sistema de Gestão Ambiental pode simultaneamente potencializar os ganhos economicos das organizações e favorecer de forma decisiva a preservação do meio ambiente.
\end{abstract}

Palavras-chave: ISO 14001, produção mais limpa, diagnóstico ambiental.

\section{Introdução}

O crescente aumento populacional mundial gerou a necessidade de maior quantidade de produtos e maior velocidade em sua manufatura; produtos artesanais de outrora já não satisfaziam mais a demanda, e a industrialização, com o advento da Revolução Industrial, veio a suprir essa necessidade. Os avanços tecnológicos desde então vem num crescente desenvolvimento sob a forma 
de novas máquinas, novos materiais e processos produtivos chegando a níveis que seriam inimagináveis a até pouco tempo atrás.

Os resíduos dos processos industriais que antes eram praticados, por serem em sua maioria de origem natural, não causavam grandes impactos ao ambiente (BIDONE,1999); já os resíduos dessa nova concepção de produção, com sua vasta gama de formas e composições repercutiram de maneira violenta, em poucas décadas, no equilíbrio ambiental do planeta.

Materiais desenvolvidos com foco apenas nas propriedades necessárias à aplicação do produto final e nos processos produtivos que visam tão somente a obtenção do máximo lucro culminaram em rejeitos de difícil decomposição, alta toxicidade, dentre outras tantas propriedades estranhas à natureza, causando os desdobramentos que se presencia na atualidade: alterações climáticas, desertos que não param de crescer, desequilíbrios nos ecossistemas.

Ambientalistas de várias partes do mundo a décadas vêm lutando em prol de atitudes para a reversão desse quadro, dentre elas pode-se citar a Conferência de Estocolmo (1972), a Assembléia Geral das Nações Unidas (1983), o relatório de Brundtland (1987) a Conferência das Nações Unidas para o Meio Ambiente (ECO 92), realizada no Brasil (consagrando o conceito de Desenvolvimento Sustentável: um modelo econômico menos consumista e mais adequado ao equilíbrio ecológico) e a Conferência Mundial sobre Desenvolvimento Sustentável realizada em Joanesburgo (2002), na África do Sul, traçando novas diretrizes para o Desenvolvimento Sustentável (aplicar o "pensar globalmente e agir localmente”).

Atrelados a isso os governos vêm impondo legislações em benefício ao meio ambiente, específicas para cada área de atuação humana, fiscalizando e punindo os infratores de forma cada vez mais severa.

Essa tendência mundial gerou um novo perfil de consumidor que, mais consciente e preocupado com a questão ambiental, agrega valor de estima aos produtos ecologicamente corretos tornando esse um dos fatores de influência na competitividade entre as empresas.

Devido a essa nova realidade as empresas estão vivenciando essa dicotomia da sustentabilidade: de um lado, no âmbito ambiental, o dever responsável para com o meio ambiente, em resposta à satisfação dos clientes; de outro lado, no âmbito econômico, as imposições legais e o valor desses procedimentos, que contribuem para aumentar seus custos.

Nesse contexto, a implementação de um Sistema de Gestão Ambiental torna-se uma alternativa atrativa às organizações por abranger a questão ambiental de forma global e sistemática, permitindo um alinhamento de cada setor com a adequação ambiental.

Em vista disso, esta pesquisa teve como objetivo exemplificar a aplicação da norma ISO 14001, no tocante ao Diagnóstico Ambiental Inicial, no setor produtivo de uma empresa de alumínio secundário na cidade de Ponta Grossa - PR, evidenciando os aspectos e impactos 
ambientais, bem como as potenciais melhorias detectadas nas atividades envolvendo desde o recebimento de matérias-primas até a obtenção dos lingotes com a composição química exigida pelo cliente.

Através da análise dos dados obtidos evidenciou-se que a aplicação desse Sistema de Gestão Ambiental pode simultaneamente potencializar os ganhos econômicos das organizações e favorecer de forma decisiva a preservação do meio ambiente.

\section{Referencial Teórico}

\subsection{ISO 14001}

A norma ISO (International Organization for Standardization) 14001, segundo Pereira, Marques e Aguiar (2003), é um sistema de normas internacionais de gestão ambiental elaborado com base nas normas britânicas que entraram em vigor em 1992, a BS7750 - Specification for Environemental Management Systems; que se aplica ao gerenciamento das atividades de organizações que tenham impactos ambientais e não uma norma de produto ou desempenho.

Nascimento e Poledna (2002), afirmam que a norma ISO 14001 esta sendo desenvolvida desde 1993 pelo Comitê Técnico (TC) 207 ISO com o objetivo de fornecer as empresas e demais organizações de todo o mundo uma abordagem comum da gestão ambiental.

Atualmente um pré-requisito fundamental para as empresas que desejam escoar seus produtos em um contexto de mercado globalizado através da melhoria de seu desempenho ambiental é obter a certificação de um Sistema de Gestão Ambiental pela ISO 14001, segundo Seiffert (2006), que determina a competitividade para as empresas de todos os perfis, sendo elas de médio ou pequeno porte.

Aplica-se a norma 14001 às empresas de atividades industriais, agroindustriais e de serviços certificando as instalações da empresa, linhas de produção e produtos que satisfaçam os padrões de qualidade ambiental (SOLEDADE et al., 2007).

Esta norma especifica os requisitos relativos a um sistema da gestão ambiental, permitindo a uma organização desenvolver e implementar uma política e objetivos que levem em conta os requisitos por ela subscritos e informações referentes aos aspectos ambientais significativos. Aplicase esta norma a qualquer organização que deseje: a) estabelecer, implementar, manter e aprimorar um sistema de gestão ambiental e b) se assegurar da conformidade com sua política ambiental definida (ABNT, 2004). 
A ISO 14001 é composta pela Política Ambiental, Planejamento, Implantação ou Operação, Verificação e Ação Corretiva e pelas Revisões Gerenciais. A Figura 1 apresenta o Sistema de Gestão Ambiental pela ISO 14001.

Figura 1 - Sistema de Gestão Ambiental pela ISO 14001.

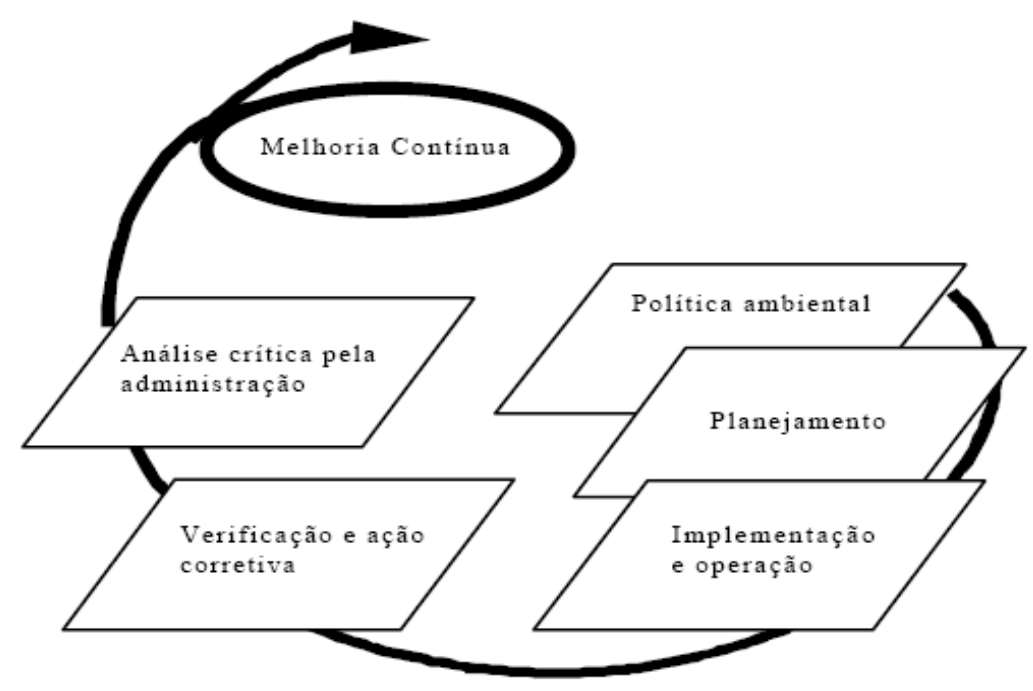

Fonte: Cajazeira, 1998.

De acordo com ABNT (2004), a norma ISO 14001 não estabelece condições absolutas para o desempenho ambiental, pois cada empresa identifica entre as suas possibilidades aqueles aspectos ambientais que pode controlar e aqueles que possam influenciar no seu desenvolvimento.

Através da ISO 14001 a empresa depois de implantá-la pode atingir os seguintes benefícios, conforme afirmam Nascimento e Poledna (2002):

a) Redução do custo de disposição dos resíduos;

b) Melhoria da imagem, da relação com os clientes;

c) Melhora no relacionamento com autoridades regulamentadoras;

d) Aumento do acesso aos fundos de investimentos;

e) Redução do seguro de investimentos;

f) Redução dos riscos de responsabilidade de despoluição;

g) Redução do custo de energia;

h) Habilidade para correção de problemas potenciais antes de causar danos ambientais;

i) Demonstração de comportamento ambiental esperado;

j) Vantagens competitivas sustentáveis através de sistemas de gestão ambiental.

O enfoque da norma ISO 14001, segundo Seiffert (2006) incorpora dois grupos: o da organização e do produto. Sendo a norma do produto dividida em: a Rotulagem ambiental 
(estabelece diferentes escopos para a concessão de selos ambientais), a Avaliação do Ciclo de Vida (constitui a sistemática para a realização da avaliação de ciclo de vida de produto) e os Aspectos ambientais em normas de produtos (buscam orientam os elaboradores de normas de produtos a especificação de critérios que reduzam os efeitos ambientais oriundos dos componentes).

\subsection{Produção mais Limpa $(\mathrm{P}+\mathrm{L})$}

A Produção mais Limpa surgiu em 1991, ocorreu em um programa da UNIDO/UNEP como uma abordagem intermediária entre a Produção Limpa do Greenpeace e a diminuição de resíduos do Environmental Protection Agency - EPA (CNTL, 2003).

Conforme Barbieri (2004), a Produção mais Limpa teve suas origens estimuladas pela Conferência de Estocolmo em 1972, com a definição de tecnologia limpa, que intenciona disseminar menos poluição ao meio ambiente, gerar menos resíduos e consumir menos recursos naturais.

De acordo com o Centro Nacional de Tecnologia Limpa - CNTL (2003), Produção mais Limpa constitui o aproveitamento contínuo de uma estratégia econômica, ambiental e tecnológica associada aos processos e produtos, a fim de aumentar a eficácia no uso de matérias-primas, água e energia através da não geração, diminuição ou reciclagem de resíduos gerados em todos os setores produtivos.

A Produção mais Limpa aplica uma abordagem preventiva na Gestão Ambiental, que permite o funcionamento da empresa de modo social e ambientalmente responsável, trazendo uma influência em melhorias econômicas e tecnológicas (CNTL, 2001; SILVA FILHO e SICSÚ, 2003), com a intenção de maximizar a eficiência na utilização das matérias-primas, água e energia, aplicada a serviços e produção, com o intuito de diminuir os riscos para as pessoas e ao meio ambiente (CNTL, 2001; SILVA FILHO e SICSÚ, 2003; PIMENTA e GOUVINHAS, 2007).

De acordo com CNTL (2002), essa tecnologia (produção mais limpa) apresenta várias vantagens quando comparada às tecnologias de fim de tubo, sendo elas:

a. Redução da quantidade de materiais e energia usados, apresentando assim um potencial para soluções econômicas;

b. A minimização de resíduos, efluentes e emissões;

c. A responsabilidade pode ser assumida para o processo de produção como um todo e os riscos no campo das obrigações ambientais e da disposição de resíduos podem ser minimizados;

d. A minimização de resíduos, efluentes e emissões. 
A Produção mais Limpa tem como objetivo fortalecer economicamente a indústria através da prevenção da poluição, colaborando com o progresso da situação ambiental de determinada região. Explora o processo produtivo e as demais atividades de uma empresa e avalia a utilização de materiais e energia. A partir disto, são criteriosamente examinados os produtos, as tecnologias e os materiais, com a intenção de diminuir os resíduos, as emissões e os efluentes, e descobrir modos de reutilizar os resíduos inevitáveis (CNTL, 2002).

Ainda segundo CNTL (2002), a Produção mais Limpa é uma ferramenta completa na determinação de escolhas para otimização do processo produtivo e melhoria contínua do processo, pois junta as questões que induzem a esse fim, como: qualidade, planejamento, segurança, meio ambiente, design, saúde ocupacional e eficiência.

A implantação da Produção mais Limpa, segundo Perretti et al. (2007) requer um monitoramento através de indicadores ambientais e de processo que proporcionem resultados relacionados a uso ecoeficiente de recursos, ocasionando um completo entendimento do sistema de gerenciamento da empresa.

O procedimento de implantação do programa de Produção mais Limpa pode ser analisado em seis fases, conforme demonstra a Figura 2.

Figura 2: Fluxograma das etapas de implantação do programa de produção mais limpa

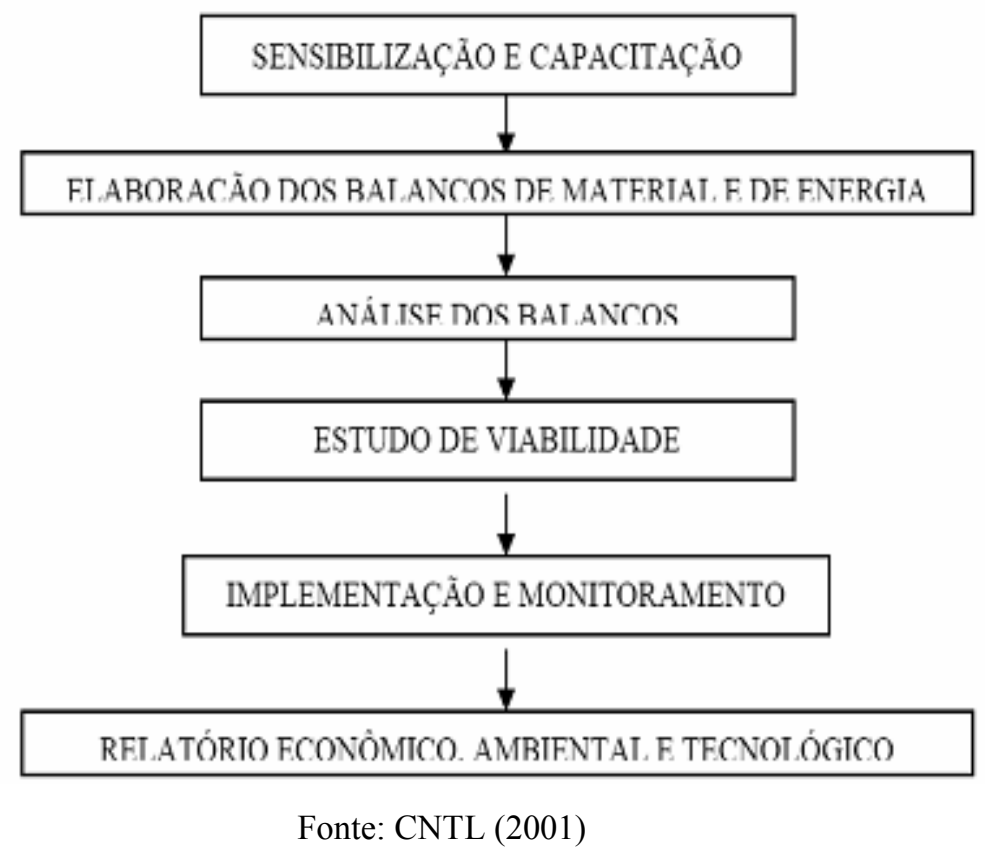

Segundo Elias, Prata e Magalhães (2004), para a implantação da Produção mais Limpa é necessário o planejamento e coordenação do fator mais relevante, que na etapa inicial é o comprometimento da gerência. Danihelka (2004) afirma que as empresas precisam gerar ações 
significativas para o retorno do investimento da metodologia da Produção mais Limpa de forma rápida.

\section{Estudo de caso}

\subsection{Método}

A presente pesquisa foi realizada no período de agosto de 2008. Teve natureza aplicada, conforme Lakatos e Marconi (2006), pois “caracteriza-se por seu interesse prático, isto é, que os resultados sejam aplicados ou utilizados, imediatamente, na solução de problemas que ocorrem na realidade", com abordagem qualitativa em relação aos temas tratados.

Do ponto de vista dos objetivos, este estudo classifica-se como exploratório, proporcionando mais intimidade com o problema, tornando-o mais explícito, aperfeiçoando as idéias e descobertas de intuição, e descritivo, tendo a definição das características de determinados fenômenos, sendo utilizadas técnicas de coletas de dados, tais como o questionário e a observação sistemática (GIL, 2002).

Em relação aos seus procedimentos técnicos como bibliográfico, sendo utilizadas dissertações, livros técnicos, artigos e periódicos; e estudo de caso, pois tem o objetivo de alcançar um conhecimento amplo e detalhado do tema a partir de um estudo profundo de um ou poucos objetos relacionados a ele (GIL, 1999 e LAKATOS e MARCONI, 2000).

Os dados foram coletados por análise de documentos, observação direta e do diagnóstico ambiental da ISO 14001, composto pela análise ambiental prévia que tem como objetivo apresentar os aspectos ambientais, estabelecer a política ambiental e análise da relevância dos aspectos levantados, sendo avaliada a caracterização, filtros de significância e identificações/padrões, e em qual nível de gerenciaento se enquadra pela Produção mais Limpa.

\subsection{Caracterização da unidade de pesquisa}

A Suprametal indústria e comércio de artefatos de alumínio Ltda. é uma empresa incubada na Universidade Tecnológica Federal do Paraná, Campus Ponta Grossa, no ramo de fundição de alumínio secundário, trabalhando com estoque zero (just in time), desde o ano de 2006.

“A missão da Supramental é fornecer ligas de alumínio, a partir da reciclagem de materiais pós-consumo e pós-venda, buscando tecnologias limpas em seus processos produtivos para obtenção de produtos com qualidade e preços competitivos, atuando com responsabilidade ambiental e social". 
A empresa possui como principais maquinários um forno elétrico à indução 100 kW e 3000 hz, capacidade de $40 \mathrm{~kg}$ de alumínio por corrida ou 48,5 kg/h e um espectrofotômetro de emissão óptica.

As matérias-primas utilizadas para a fabricação de lingotes de alumínio são: perfis, alumínio mole, latas, pistões, panelas, cabeçotes, alumínio duro, cabos e placas.

Os resíduos gerados pela empresa são predominantemente constituídos por escória (contendo aproximadamente $50 \%$ de alumínio em sua composição), que é vendida para sucateiros da região.

\subsubsection{Descrição do processo produtivo}

Primeiramente o cliente solicita a quantidade e o tipo de alumínio que deseja. Utilizando uma planilha em Excel faz-se a determinação das quantidades necessárias de cada tipo de sucata (classificadas como: perfis, alumínio mole, latas, pistões, panelas, cabeçotes, alumínio duro, cabos ou placas) considerando a composição química aproximada de cada uma. Solicitam-se os tipos e quantidades necessárias ao fornecedor das matérias-primas.

Ao receber o material é feita a pesagem e armazenamento de cada tipo de sucata. A seguir é feita uma nova pesagem dos materiais separando-os nas proporções adequadas à uma corrida e conformando-os em dimensões que possibilitem sua inserção no forno.

Realizada a fusão do material, adiciona-se o escorificante, retira-se a escória formada e é feita a vazagem e preparação do corpo de prova (amostra).

Faz-se a análise da composição química da amostra num espectrofotômetro de emissão óptica, onde é verificado se a composição química está dentro dos parâmetros requeridos pelo cliente:

- Se sim: vazar o material em lingotes e fazer a expedição de transporte terceirizado para o cliente.

- Se não: adicionar os elementos para correção e voltar ao procedimento de vazagem e preparação do corpo de prova; por fim vaza-se o material em lingotes e procede-se a expedição dos mesmos. 


\section{Resultados e Discussão}

\subsection{Diagnóstico Ambiental pela ISO 14001}

A política ambiental deve ser definida pela alta administração, sendo apropriada à escala de impactos ambientais de suas atividades, incluindo o comprometimento com a melhoria continua e com a prevenção da poluição (VITERBO JUNIOR, 1998).

Assim determinando uma Política Ambiental para a Empresa que consiste em: "promover os princípios da tecnologia no desenvolvimento sustentável, através da reciclagem de materiais pósconsumo e pós-venda, buscando tecnologias limpas em seus processos produtivos para obtenção de produtos com qualidade e preços competitivos, com iniciativas de prevenção ao meio ambiente e conformidade com a legislação ambiental, buscando a melhoria contínua".

Foram realizadas visitas à Empresa Suprametal no mês de agosto de 2008, para a avaliação prévia dos aspectos ambientais no processo produtivo determinando também os impactos ambientais mais significativos ao meio ambiente.

Os aspectos ambientais são analisados continuamente (anual, mensal, semestral), sendo definidos conforme Viterbo Junior (1998) como quaisquer elementos das atividades, produtos ou serviços que possam interagir com o meio ambiente. E os impactos ambientais como quaisquer modificações do meio ambiente, podendo ser benéficas ou adversas, que resultem em uma parte ou no todo das atividades da organização. A Tabela 1 apresenta os aspectos ambientais da empresa e sugestões de melhoria. 
Tabela 1 - Aspectos Ambientais e sugestões de melhoria

\begin{tabular}{|c|c|}
\hline ASPECTO AMBIENTAL & SUGESTÃO DE MELHORIA \\
\hline $\begin{array}{l}\text { No momento da pesagem não se tem absoluta certeza se o } \\
\text { material é alumínio }\end{array}$ & $\begin{array}{l}\text { Utilizar imãs para detectar possíveis materiais ferrosos em } \\
\text { meio à matéria-prima e utilizar esmeril para análise de } \\
\text { centelha no caso de dúvida com outro tipo de material } \\
\text { não-ferroso }\end{array}$ \\
\hline Matéria-prima não é limpa na recepção & $\begin{array}{l}\text { Implementar um processo de limpeza à matéria-prima } \\
\text { (antes da pesagem) }\end{array}$ \\
\hline Não há classificação no armazenamento & Triagem do material \\
\hline Armazenamento inadequado da matéria-prima & Armazenagem em locais pré-determinados \\
\hline $\begin{array}{l}\text { Não há procedimento determinado para conformar as } \\
\text { peças maiores }\end{array}$ & $\begin{array}{l}\text { Delimitar local e equipamentos apropriados para } \\
\text { conformação da matéria-prima nas dimensões ótimas para } \\
\text { inserção no forno }\end{array}$ \\
\hline Não utilizam EPI's & Utilizar EPI's \\
\hline Alto ruído dos exaustores & Substituição do equipamento \\
\hline $\begin{array}{l}\text { Botijão de gás (com maçarico para aquecer o molde dos } \\
\text { lingotes) obstruindo a área de trabalho }\end{array}$ & Substituição por instalações de gás adequadas \\
\hline Emissão de gases do processo & $\begin{array}{l}\text { Adquirir equipamento para o tratamento e exaustão } \\
\text { adequada desses gases }\end{array}$ \\
\hline Ergonomia das atividades & $\begin{array}{l}\text { Adequar os equipamentos às atividades considerando } \\
\text { aspectos ergonômicos }\end{array}$ \\
\hline Consumo desnecessário de energia do espectrofotômetro & $\begin{array}{l}\text { Ligar o equipamento apenas quando necessária sua } \\
\text { utilização }\end{array}$ \\
\hline $50 \%$ da escória constitue-se de alumínio & $\begin{array}{l}\text { Alterar escorificante (para agregar menos alumínio à } \\
\text { escória formada) }\end{array}$ \\
\hline Muita matéria-prima desperdiçada na varrição & Peneiramento e triagem do material de varrição \\
\hline $\begin{array}{l}\text { Amostra de composição química dos materiais } \\
\text { armazenada por tempo indeterminado }\end{array}$ & Estabelecer prazo máximo de armazenagem \\
\hline
\end{tabular}

Fonte: Autoria própria (2008)

Após ter analisado os aspectos ambientais, eles devem ser divididos em categorias, sendo classificados pela sua potencialidade de causar impactos ambientais. Devem ser feitas as determinações dos aspectos considerando as seguintes situações: condições normais de operação; condições anormais de operações e condições de emergência ambiental (VITERBO JUNIOR, 1998).

Para a identificação dos impactos ambientais significativos da empresa Suprametal, foi utilizada uma matriz de aspectos e impactos ambientais, como mostra a Tabela 2, que tem como objetivo segundo Viterbo Junior (1998) e Seiffert (2006), determinar em forma de tabela os aspectos, impactos, probabilidade de ocorrência, gravidade/severidade e probabilidade de transgredir a legislação. 
A identificação dos impactos ambientais referentes à legislação é determinada a partir do somatório da probabilidade de ocorrência x severidade. Assim os impactos significativos são definidos em relação à probabilidade $\mathrm{x}$ severidade, que resultou maior ou igual a nove. A probabilidade é definida em impactos crônicos (freqüentes) e impactos agudos (ocasionais), tendo o grau 1: baixa, grau 2: moderada e grau 3: alta. A severidade esta ligada à freqüência de ocorrência, sendo grau 1: não infringem a legislação, grau 2: implicam prejuízos de materiais na empresa e grau 3: infração legal. Os filtros de significância devem ser em relação a: escala de impactos; duração do impacto; dificuldade de alteração do impacto; efeito de uma alteração sobre outra atividade; esgotamento de recursos naturais; preocupações das partes interessadas e efeitos na imagem pública de organização.

Tabela 2 - Matriz de aspectos e impactos ambientais

\begin{tabular}{|c|c|c|c|c|c|c|c|c|c|c|}
\hline \multicolumn{2}{|c|}{ IDENTIFICAÇÃO } & \multicolumn{7}{|c|}{ CARACTERIZAÇÃO } & \multicolumn{2}{|c|}{$\begin{array}{l}\text { FILTRO DE } \\
\text { SIGNIFI } \\
\text { CANCIA }\end{array}$} \\
\hline Aspectos & Impactos & $\begin{array}{l}\mathbf{C} \\
\mathbf{L}\end{array}$ & $\begin{array}{l}\mathbf{I} \\
\mathbf{N} \\
\mathbf{C}\end{array}$ & $\begin{array}{l}\mathbf{T} \\
\mathbf{E} \\
\mathbf{M}\end{array}$ & $\begin{array}{l}\mathbf{S} \\
\mathbf{E}\end{array}$ & $\begin{array}{l}\mathbf{F} \\
\mathbf{R} \\
\mathbf{E}\end{array}$ & $\begin{array}{l}\mathbf{P} \\
\mathbf{R} \\
\mathbf{O}\end{array}$ & $\begin{array}{l}\mathbf{I} \\
\mathbf{M} \\
\mathbf{P}\end{array}$ & $\begin{array}{l}\mathbf{R} \\
\mathbf{E} \\
\mathbf{G}\end{array}$ & $\begin{array}{l}\mathbf{P} \\
\mathbf{I}\end{array}$ \\
\hline $\begin{array}{l}\text { Utilização de substâncias } \\
\text { químicas }\end{array}$ & Contaminação do solo & $\mathrm{A}$ & $\mathrm{D}$ & $\mathrm{F}$ & 3 & 3 & 2 & 8 & $\mathrm{x}$ & $\mathrm{X}$ \\
\hline Utilização de metais & $\begin{array}{l}\text { Contaminação do solo e diminuição dos } \\
\text { recursos naturais }\end{array}$ & $\mathrm{A}$ & $\mathrm{D}$ & $\mathrm{F}$ & 3 & 3 & 3 & 9 & & $\mathrm{X}$ \\
\hline $\begin{array}{l}\text { Consumo de água } \mathrm{e} \\
\text { energia }\end{array}$ & Consumo dos recursos naturais & $\mathrm{A}$ & $\mathrm{I}$ & $\mathrm{A}$ & 2 & 3 & 3 & 8 & & $\mathrm{X}$ \\
\hline Condições de trabalho & Risco de acidentes & $\mathrm{A}$ & $\mathrm{I}$ & $\mathrm{F}$ & 1 & 1 & 1 & 3 & & $\mathrm{X}$ \\
\hline $\begin{array}{l}\text { Manutenção dos } \\
\text { equipamentos }\end{array}$ & $\begin{array}{l}\text { Emissões de gases, contaminação do solo } \\
\text { e efluentes, consumo de combustível } \\
\text { (energia). }\end{array}$ & A & $\mathrm{D}$ & A & 3 & 3 & 1 & 7 & $\mathrm{x}$ & $\mathrm{X}$ \\
\hline $\begin{array}{l}\text { Armazenamento de } \\
\text { substâncias químicas }\end{array}$ & Contaminação do solo e efluentes & A & $\mathrm{D}$ & $\mathrm{F}$ & 3 & 3 & 1 & 7 & $\mathrm{x}$ & $\mathrm{X}$ \\
\hline Emissões de gases & $\begin{array}{l}\text { Poluição atmosférica e contaminação do } \\
\text { ar }\end{array}$ & A & $\mathrm{D}$ & A & 3 & 2 & 2 & 7 & $\mathrm{x}$ & \\
\hline $\begin{array}{l}\text { Geração de resíduos } \\
\text { sólidos }\end{array}$ & Contaminação do solo e da água & $\mathrm{A}$ & $\mathrm{D}$ & $\mathrm{A}$ & 2 & 1 & 2 & 5 & $\mathrm{x}$ & $\mathrm{X}$ \\
\hline Botijão de gás & $\begin{array}{l}\text { Poluição atmosférica e contaminação do } \\
\text { solo }\end{array}$ & $\mathrm{A}$ & $\mathrm{D}$ & $\mathrm{A}$ & 3 & 2 & 2 & 7 & & \\
\hline
\end{tabular}

*Legenda da matriz: CL: classe (benéfica ou adversa); INC: incidência (direta ou indireta); TEM: temporalidade (atual ou futura); SEV: severidade (1=baixa, 2=média ou 3=alta); FRE: freqüência (1=raramente, 2=periodicamente ou 3=continuamente); PROB: probabilidade (1=remota, 2=provável ou 3=muito provável); IMP: importância (somatório SEV+FRE+PROB); REG: regulamentação; PI: partes interessadas, exemplo ONGs, clientes ou poder público. 
Através da análise da matriz de criticidade, os autores selecionaram os impactos ambientais que são mais relevantes para a empresa. Para tal seleção, foi utilizado o filtro de significância, e os impactos que tiveram mais marcações nesta área da matriz, ou que tiveram presença em todas as colunas do filtro.

Vários impactos ambientais apresentaram muitas marcações no filtro de significância. Porém, como prioridade, os autores selecionaram os que apresentaram severidade igual a três, pois são os que apresentam maior risco aos funcionários da empresa, ao meio ambiente e ainda são passíveis de sanções penais, por descumprimentos de leis e normas ambientais.

Além disso, é evidente que não é possível resolver todas as não conformidades da empresa em uma única etapa. Então, os autores sugeriram que a primeira tomada de decisão de prevenção dos impactos, seria sobre as substâncias químicas e metais - contaminação do solo, água e efluentes, emissões de gases tóxicos e risco de explosões.

Após essa análise prévia dos aspectos ambientais e impactos ambientais, foi sugerido um novo processo produtivo para a empresa, como mostra a Figura 3.

Figura3- Sugestão do processo produtivo
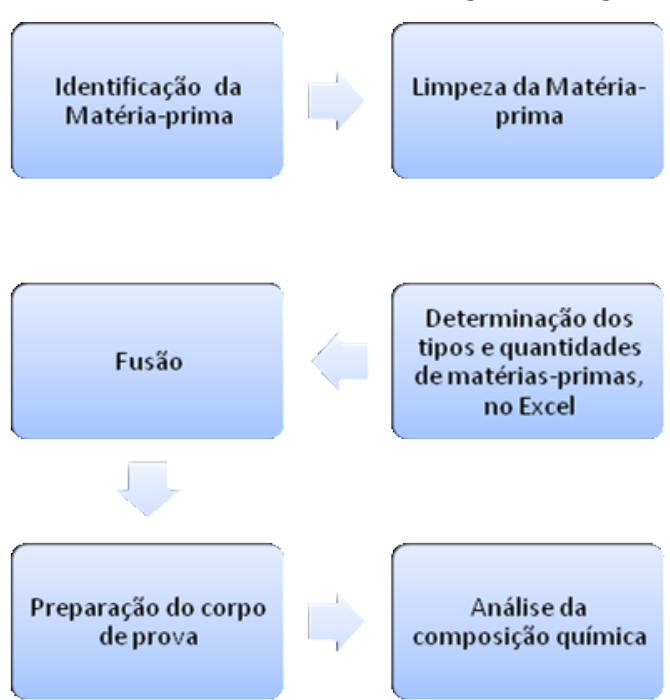
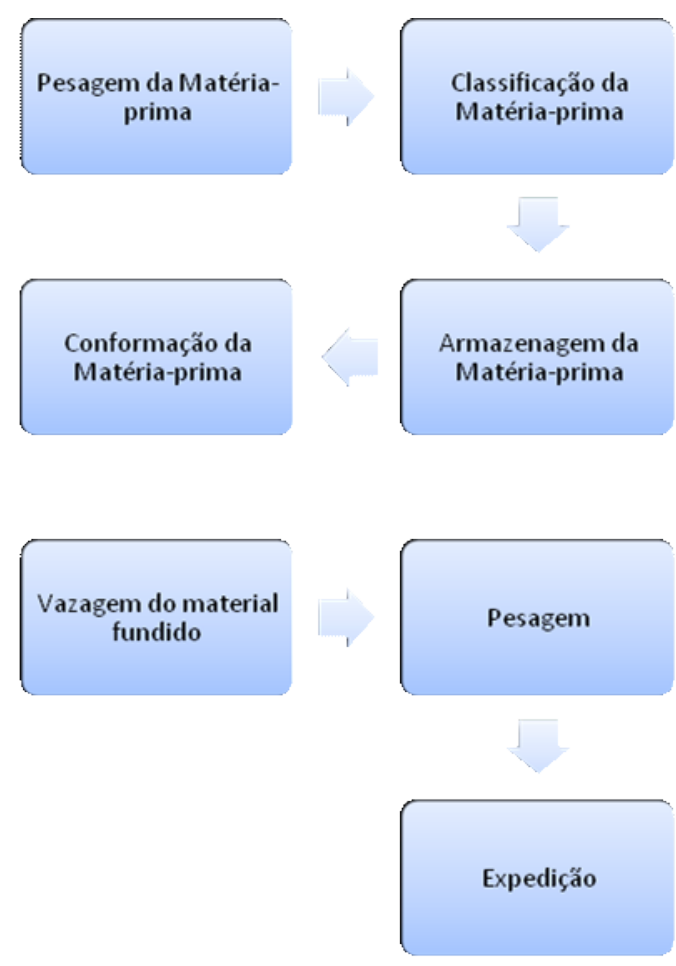

Fonte: Autoria própria (2008)

Foi determinado para a Empresa Suprametal um Programa de Gerenciamento Ambiental que tem como objetivo atingir as metas estabelecidas como esta apresentado na Tabela 3. Os planos de 
ação devem ser detalhados o mais completamente possível em atividades, visando facilitar a compreensão de todos e a decorrente implementação das ações, afirma Viterbo Junior (1998).

Ainda segundo o mesmo autor, os objetivos e metas devem ser compatíveis com a política ambiental, incluindo o comprometimento com a prevenção da poluição. Sempre que possível os objetivos e metas dever ser: S (específicos) M (mensuráveis) A (condensados) R (racionais) T (com prazo para serem atingidos). Os objetivos devem cumprir as legislações ambientais naqueles pontos que eventualmente a empresa ainda não conseguiu cumprir. E as metas devem ser monitoradas através de indicadores.

Tabela 3 - Programa de Gerenciamento Ambiental

\begin{tabular}{|l|l|}
\hline \multicolumn{2}{|c|}{ PROGRAMA DE GERENCIAMENTO AMBIENTAL } \\
\hline OBJETIVOS & METAS \\
\hline Reduzir a quantidade de resíduos & $\begin{array}{l}\text { Reduzir em 30\% a quantidade de alumínio agregado à } \\
\text { escória }\end{array}$ \\
\hline Redução no uso de energia elétrica & Reduzir o uso de energia elétrica em 10\% \\
\hline Redução no uso de produtos químicos & Reduzir do consumo de escorificante em 10\% \\
\hline Redução no consumo de água & $\begin{array}{l}\text { Reduzir o consumo de água em 5\% } \\
\text { Implantar o sistema de captação de água pluvial, para } \\
\text { utilização dos sanitários }\end{array}$ \\
\hline Melhorar a conformidade de resíduos perigosos & $\begin{array}{l}\text { Treinamento para os funcionários sobre a destinação } \\
\text { correta desses resíduos }\end{array}$ \\
\hline
\end{tabular}

Fonte: Autoria própria (2008)

\subsection{Produção mais Limpa}

A Figura 4 apresenta a abordagem de Produção mais Limpa e a declaração de prioridades na identificação de oportunidades. 
Figura 4 - Etapas de Gerenciamento da Produção mais Limpa

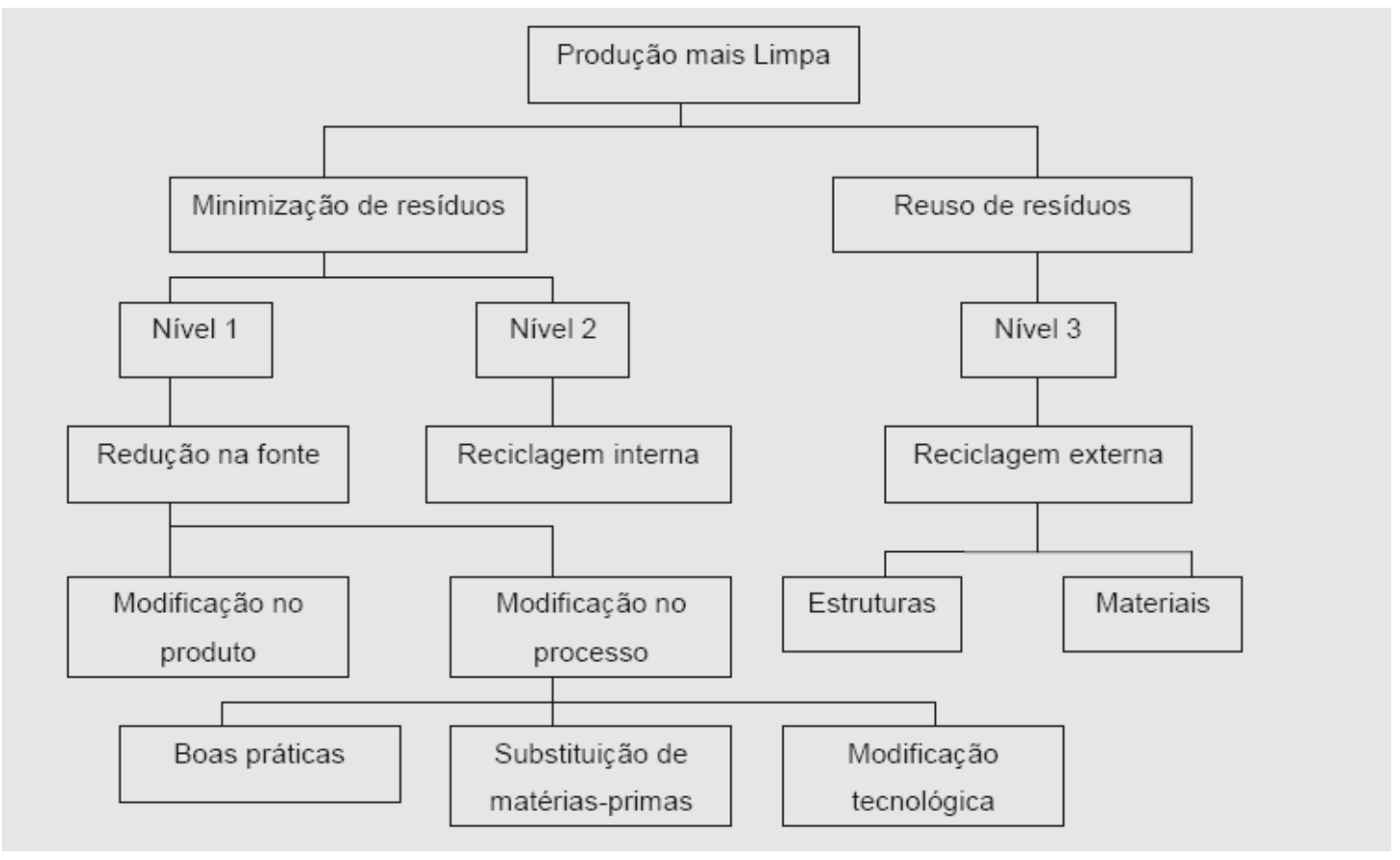

Fonte: CNTL (2003).

Foi identificado que a empresa Suprametal apresenta abordagem na Produção mais Limpa no nível 3, por realizar reciclagem externa de seus rejeitos (escória).

Considerando todos os níveis da Produção mais Limpa níveis ainda podem-se tomar decisões como:

a) Nível 1: melhoria contínua visando redução dos resíduos;

b) Nível 2: busca pela reciclagem interna da escória e das matérias-primas descartadas por varrição.

Para análise de tomada de decisão, devem-se montar as planilhas de viabilidade técnica e econômica, ao mesmo tempo gerando indicadores de desempenho ambiental, para os objetivos e metas levantados anteriormente na ISO 14001, são os fatores a serem atingidos.

\section{Considerações Finais}

A aplicação de conceitos ambientais vem se apresentando de forma cada vez mais contundente como fator base para o fomento à sustentabilidade das organizações.

Nesse ínterim os Sistemas de Gestão Ambiental apresentam-se como ferramentas imprescindíveis para o alinhamento e melhor utilização desses conceitos.

O estudo de caso apresentado exemplificou a aplicação da norma ISO 14001 através do Diagnóstico Ambiental Inicial das atividades de uma empresa de reciclagem de alumínio 
evidenciando os aspectos e impactos ambientais envolvidos em todo processo fabril, o levantamento dessas informações propiciou a prospecção de potenciais melhorias através da utilização do conceito de Produção mais Limpa.

Além dos aspectos econômicos, os pressupostos da Produção mais Limpa como a prevenção, a melhoria contínua, boas práticas, busca por inovações em produtos e processos, aplicação/avaliação da reciclagem interna e externa a tornam plenamente integrável aos demais sistemas de gestão.

A aplicação da ISO14001 em conjunto com a Produção mais Limpa contribui efetivamente para a melhoria da competitividade das organizações através de benefícios como, por exemplo, aumento da produtividade, melhoria da qualidade, otimização de recursos naturais, insumos e energia, fatores esses de importância relevante à necessidade da busca contínua da excelência empresarial podendo simultaneamente potencializar os ganhos econômicos das organizações e favorecer de forma decisiva a preservação do meio ambiente.

\begin{abstract}
The application of environmental concepts is appearing in an ever more compelling factor as a basis for promoting the sustainability of organizations. In the Environmental Management Systems are presented as indispensable tools for alignment and better use of these concepts. In view of this, we aimed to exemplify the application of ISO 14001, regarding the Environmental Assessment Home, in the productive sector of a company's secondary aluminum in the city of Ponta Grossa-PR, pointing out the aspects and impacts, as well as identified potential improvements in activities involving from receipt of raw materials to obtain the ingots with the chemical composition required by the client. The principle theme is contextualized against the changing environmental trends and is made a literature review on ISO 14001 and the concept of cleaner production, followed by their analysis of the case study made it evident that the implementation of Environmental Management System can simultaneously maximize the economic gains of the organizations and promote a dramatic impact on environmental preservation.
\end{abstract}

Key-words: ISO 14001, cleaner production, environmental diagnosis.

\title{
Referências
}

ABNT - Associação Brasileira de Normas Técnicas. Sistema de Gestão Ambiental - Diretrizes Gerais sobre princípios, sistemas e técnicas de apoio. NBR ISO 14001. Rio de Janeiro, 2004.

BARBIERI, J. C. Gestão ambiental empresarial: conceitos, modelos e instrumentos. São Paulo: Saraiva, 2004.

BIDONE, F. R. A. Metodologia e técnicas de minimização, reciclagem e reutilização de resíduos sólidos urbanos. Rio de Janeiro: ABES (Associação de Engenharia Sanitária e Ambiental), 1999.

CAJAZEIRA, J. E. R. ISO 14001 - Manual de Implantação. Rio de Janeiro: Qualitymark, 1998.

CNTL - Centro Nacional de Tecnologias Limpas. Manual de questões ambientais e produção mais limpa. Curso de Formação de Consultores em Produção mais Limpa, Fortaleza, dezembro, 2001.

CNTL - Centro Nacional de Tecnologias Limpas. Manual metodologia de implantação do programa de produção mais limpa. Curso de Consultores em Produção mais Limpa, Fortaleza, janeiro, 2002.

CNTL - Centro Nacional de Tecnologias Limpas. Curso de Formação de Consultores em Produção mais Limpa para Pequena e Microempresa. Módulo 1, Porto Alegre: CNTL, 2003.

DANIHELKA, P. Subjective factors of Cleaner Production - parallel to risk perception? Journal of Cleaner Production, London, v. 12, 581-584 p., 2004. 
DINIZ, A. G. F. Produção mais Limpa: uma metodologia para o desenvolvimento sustentável, 2007, 98p. Dissertação (Engenharia de Produção), Universidade Tecnológica Federal do Paraná, Ponta Grossa, 2007.

ELIAS, S. J. B.; PRATA, A. B.; MAGAlHÃES, L. C. Experiência de implantação da Produção mais Limpa: estudo de múltiplos casos. In: XXIV Encontro Nacional de Engenharia de Produção, Florianópolis, Santa Catarina, novembro, 2004.

GIL, A. C. Métodos e Técnicas de Pesquisa Social. São Paulo: Atlas, 1999.

LAKATOS, E. M.; MARCONI, M. A. Metodologia Científica. $3^{\circ}$ ed., São Paulo: Atlas, 2000.

LIMA, I. M.; MATTOS, K. M. C.; MEDEIROS, V. R. F. Produção mais Limpa em fazenda de produção de camarões: uma proposta de protocolo para a implementação da metodologia. In: XXVII Encontro Nacional de Engenharia de Produção, outubro, 2007.

MOURA, L. A. Economia ambiental - gestão de custos e investimentos. São Paulo: Juarez de Oliveira, 2000.

NASCIMENTO, L. F. M.; POLEDNA, S. R. C. O processo de implantação da ISO 14000 em empresas brasileiras. In: XXII ENEGEP - Encontro Nacional de Engenharia de Produção, Curitiba, outubro, 2002.

PEREIRA, M. A.; MARQUES, C. S. A.; AGUIAR, E. M. Sugestões para uma proposta do uso de novas ferramentas tecnológicas de informações para um sistema de gestão ambiental - ISO 14000. Revista Engenharia Sanitária e Ambiental, vol. 8, n. 1, abril-junho, 2003, p. 49-53.

PERRETTI, G. A. et al. Vantagens da Implantação da Produção mais Limpa. In: $1^{\text {st }}$ International Workshop Advances in Cleaner Production, november, 2007.

PIMENTA, H. C.; GOUVINHAS, R. P. Implementação da produção mais limpa na indústria de panificação de Natal - RN. In: XXVII Encontro Nacional de Engenharia de Produção, Foz do Iguaçu, Paraná, outubro, 2007.

SEIFFERT, M. E. B. ISO 14001 Sistemas de Gestão Ambiental: Implantação objetiva e econômica. 2ed., São Paulo: Atlas, 2006.

SILVA FILHO, J. C. G.; SICSÚ, A. B. Produção mais Limpa: uma ferramenta da Gestão Ambiental aplicada às empresas nacionais. In: XXIII Encontro Nacional de Engenharia de Produção, Ouro Preto, Minas Gerais, outubro, 2003.

SOLEDADE, M. G. M. et al. ISO 14000 e a Gestão Ambiental: uma reflexão das praticas ambientais corporativas. In: IX ENGEMA - Encontro Nacional sobre Gestão Empresarial e Meio Ambiente, Curitiba, novembro, 2007.

VITERBO JUNIOR, E. Sistema integrado de gestão ambiental: como implementar um sistema de gestão que atenda à norma ISO 14001 a partir de um sistema baseado na norma ISO 9000. São Paulo: Aquariana, 1998.

\title{
DADOS DOS AUTORES:
}

\author{
Nome completo: Caroline Rodrigues Vaz
}

Filiação institucional: UTFPR-PG

Departamento: PPGEP

Função ou cargo ocupado: Mestranda

Endereço completo para correspondência (bairro, cidade, estado, país e CEP): rua: santa Lúcia, 136, Uvaranas-Borsato. CEP: 84033-150, Ponta Grossa - PR. 
Telefones para contato: 42-99309127

e-mail: caroline-vaz@hotmail.com

Nome completo: Alexandre Borges Fagundes

Filiação institucional: UTFPR-PG

Departamento: PPGEP

Função ou cargo ocupado: Mestrando

Endereço completo para correspondência (bairro, cidade, estado, país e CEP): rua: Dona Elsa Meinert, 531, bloco A3, apto. 208, bairro Costa e Silva, CEP: 89218-650. Joinville - SC.

Telefones para contato: 47 - 91023657

e-mail: borges.fagundes@gmail.com

Nome completo: Ivanir Luiz de Oliveira

Filiação institucional: UTFPR-PG

Departamento: PPGEP

Função ou cargo ocupado: Professor Orientador

Endereço completo para correspondência (bairro, cidade, estado, país e CEP): av. Monteiro Lobato, km 4, Santa Monica, CEP:84016-210. Ponta Grossa - PR.

Telefones para contato: 42- 32204874

e-mail: ivanir@utfpr.edu.br

Recebido para publicação em: 20/10/2009

Aceito para publicação em: 04/12/2009 